\title{
Behavioral and Electrophysiological Evidence for Opioid Tolerance in Adolescent Rats
}

\author{
Susan L Ingram*,', Erin N Fossum' and Michael M Morgan' \\ 'Department of Psychology, Washington State University Vancouver, Vancouver, WA, USA
}

\begin{abstract}
Morphine and other opiates are successful treatments for pain, but their usefulness is limited by the development of tolerance. Given that recent studies have observed differential sensitivity to drugs of abuse in adolescents, the aim of this study was to assess antinociceptive tolerance to morphine in adolescent rats using both behavioral and cellular measures. Early (28-35 days postnatal) and late (50-59 days) adolescent and adult (73-75 days) male rats were injected with morphine ( $5 \mathrm{mg} / \mathrm{kg}$, s.c.) or saline twice a day for two consecutive days. On Day 3, tolerance to morphine was evident in morphine-pretreated rats when tested on the hot plate test. Although baseline latencies for the early compared to late adolescent rats were faster, the magnitude of the shift in $\mathrm{ED}_{50}$ for morphine was similar for the two adolescent groups. However, the shift in $\mathrm{ED}_{50}$ tended to be greater in adolescent compared to adult rats. Subsequent to behavioral testing, whole cell patch-clamp recordings were made from ventrolateral PAG neurons. The opioid agonist, met-enkephalin (ME), activated similar outward currents in PAG neurons of early and late adolescent rats. However, reversal potentials of ME-induced currents were shifted to more hyperpolarized potentials in cells from morphine-pretreated rats. In addition, ME induced larger currents in morphine-pretreated rats with faster hot plate latencies compared to the mean (more tolerant) than in rats with slower latencies. These results indicate that repeated intermittent administration of morphine produces tolerance in adolescent rats that is associated with novel changes in opioid-sensitive ventrolateral PAG neurons.

Neuropsychopharmacology (2007) 32, 600-606. doi: I 0. I038/sj.npp. I 30 I I39; published online 28 June 2006
\end{abstract}

Keywords: opioid tolerance; adolescence; morphine; antinociception; periaqueductal gray; G-protein activated inwardly rectifying potassium channel

\section{INTRODUCTION}

Maturation of brain circuitry during development influences sensitivity to the behavioral and addictive properties of abused drugs (for reviews, Chambers et al, 2003; Adriani and Laviola, 2004). Neural development may be particularly labile during adolescence, and this may be the reason that drug exposure during adolescence is strongly associated with the development of drug dependence (Smith, 2003). The adolescent rodent is considered a valid model for developmental changes in vulnerability to drugs of abuse (Spear and Brake, 1983; Laviola et al, 1999). For example, sensitivity to morphine-induced locomotion is more evident in adolescent compared to adult rats (Spear et al, 1982) and novelty seeking and amphetamine sensitization are greater in adolescents (Adriani and Laviola, 2004). On the other hand, morphine and cocaine-induced conditioned place

*Correspondence: Dr SL Ingram, Department of Psychology, Washington State University Vancouver, 14204 NE Salmon Creek Ave, Vancouver, WA 98686, USA, Tel: + I 360546 9748, Fax: + I 360 546 9038, E-mail: ingram@vancouver.wsu.edu

Received II December 2005; revised 2 I April 2006; accepted 22 May 2006

Online publication: 30 May 2006 at http://www.acnp.org/citations/ Npp053006050732/default.pdf preference do not appear to differ in adolescent and adult rats (Campbell et al, 2000) indicating that not all drugrelated behaviors are enhanced during adolescence.

Morphine and other opiates are the most commonly used treatments for severe pain. A limiting factor in the usefulness of long-term opiate administration for pain is tolerance, a decreased effect of a drug after repeated exposure (McQuay, 1999). Little is known about sensitivity to systemic morphine and the development of morphine tolerance in adolescents. The opioid system changes throughout early postnatal development in rats (reviewed in Marsh et al, 1997) and these changes result in different sensitivities to opioid-induced antinociception and tolerance in different age rats (Fanselow and Cramer, 1988; Windh et al, 1995; Thornton et al, 1997; Zhu and Barr, 2003).

Systemic administration of opiates inhibit pain, in part, by activating a descending modulatory system that includes the periaqueductal gray (PAG), rostral ventromedial medulla (RVM) and spinal cord (Basbaum and Fields, 1984; Fields et al, 1991, 1995). Microinjection of morphine into the PAG or RVM results in antinociception (Jacquet and Lajtha, 1974; Yaksh et al, 1976; Jensen and Yaksh, 1986; Morgan et al, 1998) and antinociception induced by systemic administration of morphine is attenuated by 
inactivation of the PAG or RVM (Proudfit, 1980; Young et al, 1984; Heinricher et al, 1997; Lane et al, 2005). The ventrolateral PAG is also important in the development of tolerance to the antinociceptive effects of systemic morphine. Tolerance to systemic morphine does not occur if the action of morphine is blocked in the ventrolateral PAG with microinjections of the opiate antagonist, naltrexone (Lane et al, 2005).

These in vivo studies are supported by in vitro data showing that chronic morphine administration induces profound changes in ventrolateral PAG neurons, including decreased opioid activation of GIRK channels (Chieng and Christie, 1996; Ingram et al, 1998; Hack et al, 2003; Bagley et al, 2005) and increased opioid inhibition of presynaptic GABA release (Chieng and Christie, 1996; Ingram et al, 1998; Hack et al, 2003; Bagley et al, 2005). Studies with GIRK knockout mice have demonstrated that postsynaptic $\mu$-opioid receptor coupling to the GIRK channel is important for the antinociceptive effects of morphine (Ikeda et al, 2002; Blednov et al, 2003; Mitrovic et al, 2003; Marker et al, 2005) and suggest that postsynaptic $\mu$-opioid receptor coupling to GIRK channels in PAG neurons may contribute to opioid tolerance.

Although changes are evident in both in vivo and in vitro studies after chronic morphine administration, the cellular changes are not always consistent with behavioral measures of tolerance. For example, $\mu$-opioid receptors inhibit GABA release more potently after chronic morphine administration (Ingram et al, 1998; Hack et al, 2003), an effect that should produce antinociception by increasing the activity of PAG output neurons. One possible explanation for this inconsistency may be the age differences in the rats used for behavioral studies (adults) and electrophysiological experiments (adolescents). The purpose of this study was to directly compare the behavioral tolerance and cellular adaptations to repeated morphine administration in adolescent rats.

\section{METHODS}

\section{Subjects}

Three groups of Sprague-Dawley male rats distinguished by age were used. Early adolescent rats ranged in age from 28 to 35 days (mean age $=30 \pm 0.3$ days; $111 \pm 3 \mathrm{~g} ; n=51$ ) and late adolescent rats ranged in age from 50 to 59 days (mean age $=53 \pm 0.3$ days; $260 \pm 4 \mathrm{~g} ; n=50$ ). An additional group of adult male rats ranged in age from 73 to 75 days (mean age $=74 \pm 0.3$ days; $340 \pm 5 \mathrm{~g} ; n=15$ ). Animals were housed two per cage throughout the experiment. Food and water were available ad lib. Lights were maintained on a reverse $12: 12$ cycle (on at 19:00) so testing could be conducted during the active dark phase. Experiments were conducted in accordance with the animal care and use guidelines of the International Association for the Study of Pain and approved by the Animal Care and Use Committee at Washington State University.

\section{Nociceptive Test}

The hot plate test consisted of placing the rat on a hot plate $\left(52^{\circ} \mathrm{C}\right)$ and measuring the latency to lick a hind paw or attempt to jump out of the apparatus. As initial baseline latencies were different for each age group, a cutoff greater than four STD of the mean (40s) was used in the data analyses for all groups so the relative change to produce antinociception was consistent between age groups (Morgan et al, 2006).

\section{Experiment 1 -Development of Tolerance in Early and Late Adolescent Rats}

Immediately following a baseline hot plate test, rats were injected with saline or morphine $(5 \mathrm{mg} / \mathrm{kg}$, s.c.). Rats received injections twice a day for 2 days (Trials 1-4). Rats were returned to their cages immediately following each injection. On Trials 1 and 3, nociception was assessed using the hot plate test $30 \mathrm{~min}$ after the injection. All rats were injected with morphine ( 5 or $10 \mathrm{mg} / \mathrm{kg}$, s.c.) on Trial 5 and were tested on the hot plate to determine whether tolerance had developed to the antinociceptive effect.

\section{Experiment 2-Dose-Response Relationships in Adolescent Rats}

This study was similar to Experiment 1, except that a cumulative dosing procedure was used to determine the magnitude of tolerance using $\mathrm{ED}_{50}$ values. Tolerance was induced as in Experiment 1, except that rats were only tested on the hot plate on Trials 1 and 5. On Trial 5, rats were tested using a cumulative dose procedure: immediately after a baseline test on the hot plate test, five successive injections of morphine $(1.8,1.4,2.4,4.4$ and $8 \mathrm{mg} / \mathrm{kg}$, s.c.) were given at $20 \mathrm{~min}$ intervals resulting in quarter log doses $(1.8,3.2,5.6,10$, and $18 \mathrm{mg} / \mathrm{kg}$, s.c.). Rats were tested using the hot plate test $15 \mathrm{~min}$ after each injection.

\section{Experiment 3-Electrophysiological Recordings}

The objective of the electrophysiological recordings was to determine whether tolerance produced by intermittent administration of morphine induced changes in the response of PAG neurons to opioids. Given that tolerance lasts for approximately 1 week following repeated injections (Morgan et al, 2005), rats were anesthetized with Halothane and decapitated one to three days after the last injection (early adolescent rats $=35 \pm 1$ day and late adolescent rats $=60 \pm 1$ day). Adult rats were not used for recordings because of the difficulty in recording from mature brain tissue. Brains were removed quickly and immersed in ice-cold artificial cerebrospinal fluid (ACSF) containing (in $\mathrm{mM}$ ): $126 \mathrm{NaCl}$; 21.4 $\mathrm{NaHCO}_{3} ; 11.1$ dextrose; $2.5 \mathrm{KCl} ; 2.4 \mathrm{CaCl}_{2} ; 1.2 \mathrm{MgCl}_{2}$; $1.2 \mathrm{NaH}_{2} \mathrm{PO}_{4}, \mathrm{pH} 7.35$ and equilibrated with $95 \% \mathrm{O}_{2} / 5 \% \mathrm{CO}_{2}$. Coronal brain slices containing the ventral PAG were cut with a vibratome $(250-300 \mu \mathrm{m}$ thick) and placed into a holding chamber with oxygenated ACSF maintained at approximately $32^{\circ} \mathrm{C}$ until needed for recording.

Brain slices were placed into a recording chamber mounted on an Olympus BX51 upright microscope and superfused with heated ACSF at $2 \mathrm{ml} / \mathrm{min}$. Cells were viewed with a water immersion $40 \times$ objective (Olympus) and Nomarski infra-red optics. Recordings were made with electrodes pulled to $2-4 \mathrm{M} \Omega$ resistance with internal solutions consisting of (in $\mathrm{mM}$ ): 138 potassium gluconate 
(or potassium methylsulfate); $10 \mathrm{HEPES} ; 10 \mathrm{KCl} ; 1 \mathrm{MgCl}_{2} ; 1$ EGTA; $0.3 \mathrm{CaCl}_{2} ; 4 \mathrm{MgATP} ; 3 \mathrm{NaGTP}, \mathrm{pH}$ 7.4. Junction potentials were calculated (JPCalc, Axon Instruments, Foster City, CA, USA) and corrected at the beginning of the experiments. Capacitance and series resistance compensation $(>70 \%)$ were corrected and access resistance was monitored throughout the experiments. Data were collected with a Multiclamp 700A amplifier (Molecular Devices, Sunnyvale, CA) at $5-10 \mathrm{kHz}$ and low-pass filtered at $2-5 \mathrm{kHz}$. Currents were digitized with Digidata $1322 \mathrm{~A}$, collected via Axograph Data Acquisition software and analyzed using Axograph (Molecular Devices). Experiments were monitored with Chart software (MacLab; ADInstruments, Castle Hill, NSW, Australia). Neurons were voltageclamped at -60 or $-70 \mathrm{mV}$ and current-voltage relationships were determined with $10 \mathrm{mV}$ voltage steps from -120 to $-20 \mathrm{mV}$ in control, during drug superfusion and after recovery from drug superfusion. The $\mu$-opioid agonist met-enkephalin $(10 \mu \mathrm{M})$ and the $\mathrm{GABA}_{\mathrm{B}}$ agonist, baclofen $(20 \mu \mathrm{M})$ stimulate GIRK channels in ventrolateral PAG neurons. However, approximately $30 \%$ of ventrolateral PAG neurons respond to ME whereas almost all neurons respond to baclofen (Osborne et al, 1996). Therefore, baclofen was used as a control to determine if the morphine treatments were specific to the opioid-mediated response. The druginduced conductances were defined as the current induced in the presence of drug minus the average of the conductance before and after wash-out of drug application. Slopes of the conductances were estimated from a linear regression of the current-voltage relationship from -40 to $-90 \mathrm{mV}$. The $\%$ increase in the slope was calculated as follows: the slope in the presence of ME $(20 \mu \mathrm{M})$ divided by the average of the slope conductance before and after washout of the ME multiplied by $100 \%$. In some cells, large voltage-dependent potassium conductances were evident at $-40 \mathrm{mV}$, so amplitudes at $-40 \mathrm{mV}$ were extrapolated from the linear portion of the current-voltage relationship between $-50 \mathrm{mV}$ and $-90 \mathrm{mV}$.

\section{Drugs}

Morphine sulfate was obtained from the National Institute on Drug Abuse and diluted in saline for injections. ME and baclofen were obtained from Sigma (St Louis, MO) and diluted in appropriate buffers as concentrated stocks for further dilution in ACSF solution.

\section{Statistics}

All data are expressed as mean \pm SEM, unless otherwise noted. Differences between groups were assessed using Student's $t$-test and ANOVA when appropriate. $\mathrm{ED}_{50} \mathrm{~s}$ were estimated with non-linear regression (GraphPad Prism, San Diego, CA) of the mean hot plate latencies at each dose of morphine. Differences between groups were determined using the $95 \%$ confidence interval of the $\mathrm{ED}_{50}$ of saline-pretreated rats.

\section{RESULTS}

\section{Experiment 1: Development of Tolerance in} Adolescent Rats

Baseline latencies on the hot plate test were significantly slower for early adolescent rats $(18.5 \pm 1.0 \mathrm{~s} ; n=39)$ compared to late adolescent rats $(12.4 \pm 1.0 \mathrm{~s} ; n=38$; $t(75)=4.698, \quad p<0.05)$. Administration of morphine $(5 \mathrm{mg} / \mathrm{kg})$ on Trial 1 increased hot plate latencies in both early $(38.2 \pm 3.1 \mathrm{~s} ; n=20)$ and late $(32.5 \pm 4.7 \mathrm{~s} ; n=20)$ adolescent rats compared to saline-pretreated controls $(13.6 \pm 2.8 \mathrm{~s} ; n=19$ and $12.3 \pm 3.0 \mathrm{~s} ; n=18$, respectively; main effect of DRUG, $\mathrm{F}(1,73)=193, p<0.05)$. On Trial 5, saline- and morphine-pretreated rats were injected with morphine to measure tolerance (Figure 1). One group of rats was tested with the treatment dose of morphine $(5 \mathrm{mg} /$ $\mathrm{kg}$ ) and the other group was tested with a higher dose $(10 \mathrm{mg} / \mathrm{kg})$. Morphine $(5 \mathrm{mg} / \mathrm{kg})$ produced antinociception in saline-pretreated rats but not in morphine-pretreated rats regardless of age (main effect of PRETREATMENT, $\mathrm{F}(1,69)=26.6 ; p<0.05)$ indicating that morphine pretreatment induced tolerance. Injection of the higher morphine dose $(10 \mathrm{mg} / \mathrm{kg})$ produced similar latencies on the hot plate test in both saline- and morphine-pretreated early adolescent rats ( $40 \pm 0 \mathrm{~s} ; n=8$ and $34.2 \pm 3.6 \mathrm{~s} ; n=8$; respectively) and late adolescent rats $(36.3 \pm 3.4 \mathrm{~s} ; n=8$ and $37.1 \pm 2.5 \mathrm{~s}$; $n=8$; respectively). These results suggest that the morphine-pretreated rats are tolerant to morphine $(5 \mathrm{mg} / \mathrm{kg})$ but that a higher test dose $(10 \mathrm{mg} / \mathrm{kg})$ can overcome the tolerance.


Figure I Tolerance develops to morphine-induced antinociception in adolescent rats. After baseline testing (BL), rats were given injections of either saline or morphine $(5 \mathrm{mg} / \mathrm{kg}$, s.c.) twice a day for 2 days (Trials I-4) and tested on the hot plate test on Trials I, 3 and 5. All rats were injected with morphine $(5 \mathrm{mg} / \mathrm{kg}$, s.c.) on Trial 5. Morphine $(5 \mathrm{mg} / \mathrm{kg})$ produced significantly less antinociception on the hot plate test in morphine pretreated compared to saline pretreated (a) early adolescent rats and (b) late adolescent rats indicating the development of tolerance. $(* 0<0.05)$. 
Experiment 2: Dose-Response Relationships after Induction of Tolerance

The data from Experiment 1 suggest there are dose dependent differences in the expression of tolerance. In order to test this in more detail, rats were pretreated with injections of morphine $(5 \mathrm{mg} / \mathrm{kg}$ ) or saline as in Experiment 1 , but dose response curves to morphine were generated on Trial 5 in order to compare the magnitude of the shift in morphine potency between early and late adolescent rats. A group of adult rats was also included for comparison.

$\mathrm{ED}_{50}$ values for the effect of morphine on hot plate latencies were increased in all age groups pretreated with morphine (Table 1). Figure 2 shows the right-hand shift in the dose-response relationship in morphine-pretreated rats compared to saline-pretreated controls in all age groups indicating the development of tolerance. Although $\mathrm{ED}_{50}$ values were lower in the early compared to late adolescent rats, the shift in the dose response curves were comparable (Table 1). However, the magnitude of the shift tended to be greater in younger rats (see Figure 2).

\section{Experiment 3: $\mu$-Opioid Receptor Activation of the GIRK Channel in Tolerant Rats}

Activation of the $\mu$-opioid receptor by the opioid agonist, met-enkephalin (ME), induces an outward current in a subpopulation of ventrolateral PAG neurons through activation of the GIRK channel (Chieng and Christie, 1994). Whole-cell patch-clamp recordings were performed from PAG neurons in slices taken from morphine and salinepretreated rats 1-3 days after the Trial 5 morphine injection. ME induced outward currents in a subpopulation of PAG neurons when voltage-clamped at a holding potential of -60 or $-70 \mathrm{mV}$ (Figure 3a). The percent increase in slope conductance over control elicited by $\mathrm{ME}$ was similar in early and late adolescent rats (Figure $3 \mathrm{~b}$ ). The reversal potentials of the ME-induced currents were significantly shifted to the left in morphine-pretreated rats compared to saline-pretreated rats $(\mathrm{F}(1,24)=4.782$; $p<0.05$; Figure $3 \mathrm{c})$. The shift in reversal potential was consistent in both the early and late adolescent rats indicating that the sensitivity to repeated morphine administration is similar at both ages. It has been previously demonstrated that chronic morphine administration induces a GABA transporter-mediated cation conductance that reverses at $-40 \mathrm{mV}$ that is inhibited by opioids (Bagley et $a l, 2005)$. As the shift in the reversal potential of the ME

Table I ED 50 Values for Morphine-Induced Antinociception on the Hot Plate Test

\begin{tabular}{lccc}
\hline Pretreatment & $\begin{array}{c}\text { Early } \\
\text { adolescent }\end{array}$ & $\begin{array}{c}\text { Late } \\
\text { adolescent }\end{array}$ & Adult \\
\hline Saline & $4.2(3.4-5.0)$ & $6.9(5.6-8.2)$ & $6.2(-4.5-7.8)$ \\
Morphine & $7.7(6.0-9.4)^{*}$ & $11.1(9.1-13.1)^{*}$ & $8.6(6.9-10.3)^{*}$ \\
Fold Increase in ED 50 & 1.8 & 1.6 & 1.4 \\
\hline
\end{tabular}

Rats were pretreated with either saline or morphine $(5 \mathrm{mg} / \mathrm{kg}$, s.c.) twice a day for 2 days and tested with cumulative doses of morphine on Day 3. 95\% confidence levels are listed in parentheses $(* p<0.05)$. conductance is consistent with this, the amplitude of the ME-induced current at $-40 \mathrm{mV}$ (the voltage where the additional cation current is minimal) was also compared between groups in order to isolate the ME-induced GIRK conductance. There were no differences in the amplitudes of the ME-induced currents observed in any group (Figure $3 \mathrm{~d}$ ) indicating that morphine pretreatment did not affect the ability of ME to activate the GIRK conductance. There also were no differences in the magnitudes of baclofen-mediated conductances or reversal potentials (data not shown).

As each rat was tested on the hot plate test prior to looking at the ability of ME to activate the GIRK channels, we tested whether the amplitude or reversal potentials of the GIRK currents could be linked to tolerance to morphine.
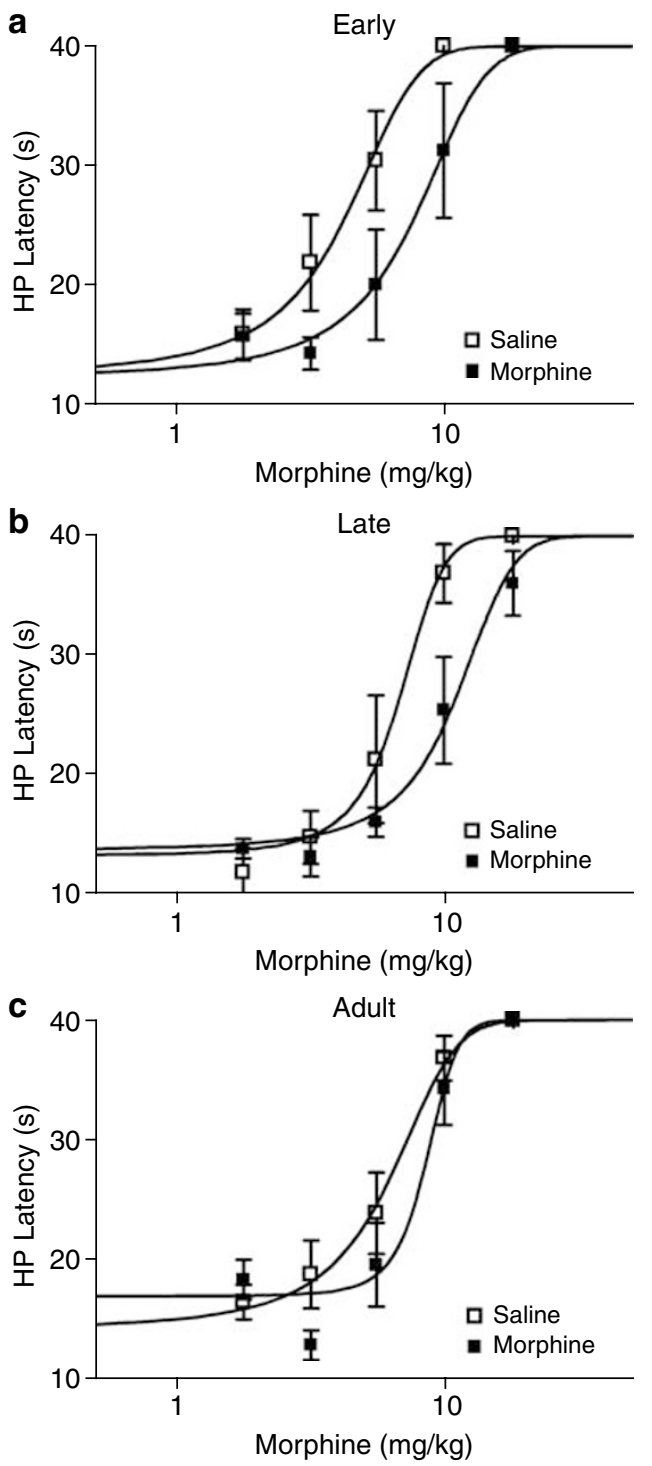

Figure 2 Repeated morphine injections shift the dose response curves for morphine on the hot plate test. Cumulative dose response curves for morphine antinociception on the hot plate test in saline and morphine pretreated (a) early adolescent, (b) late adolescent and (c) adult rats. Morphine pretreatment caused a comparable shift in the dose-response curve in early and late adolescent rats but a trend for a smaller shift was apparent in adult rats. $\mathrm{ED}_{50}$ values are listed in Table I. 
a
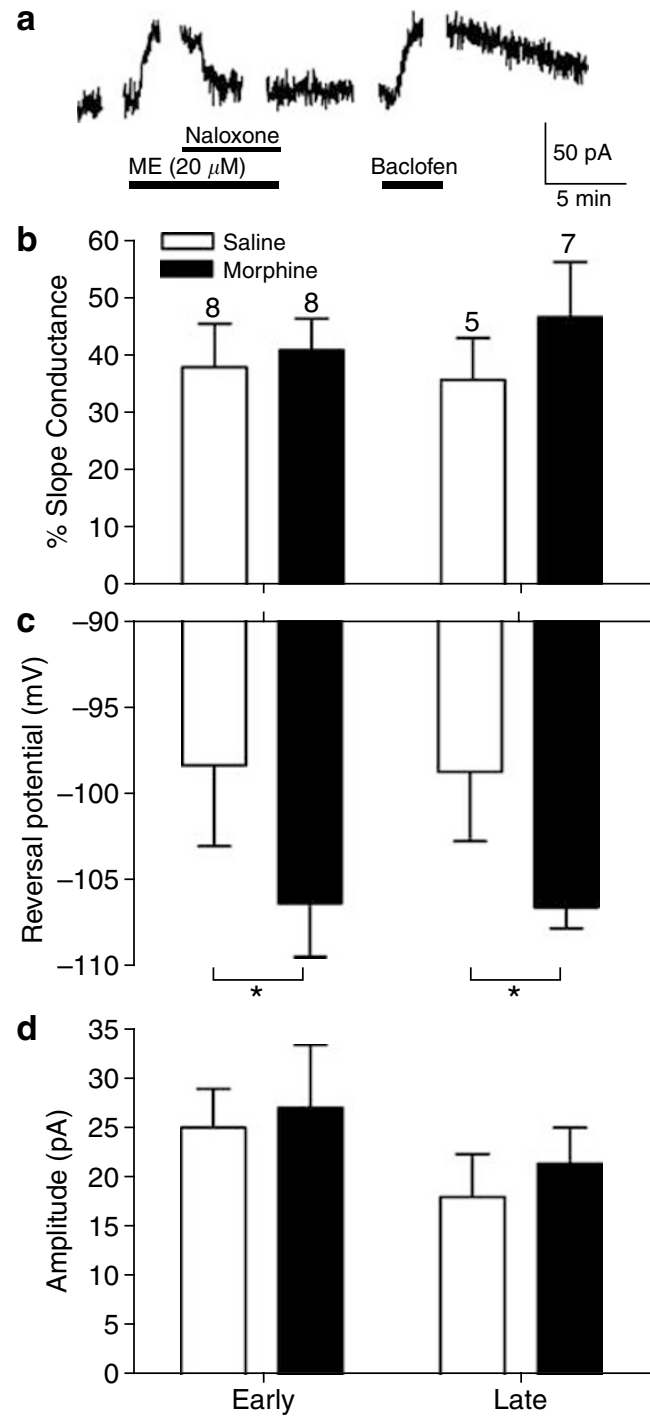

Figure $3 \mu$-Opioid receptor activation of the GIRK channel in tolerant rats. (a) Whole-cell patch-clamp recording from a ventrolateral PAG neuron held at $-60 \mathrm{mV}$ during superfusion of the nonselective opioid agonist, met-enkephalin (ME), the opioid antagonist, naloxone, and the $\mathrm{GABA}_{\mathrm{B}}$ agonist, baclofen (application denoted by bars). ME and baclofen activate outward currents. The ME effect is blocked with naloxone. Spaces in trace are where voltage jumps were made for current-voltage relationships. This recording was taken from a morphine-pretreated early adolescent rat. (b) Bar graph showing the ME-induced \% increase in slope conductance from control in saline- and morphine-pretreated adolescent rats. There are no significant differences in the magnitude of the MEinduced conductance between groups. The number of neurons is indicated with numbers above bars. (c) Bar graph showing the reversal potentials of the ME-induced conductances from saline- and morphine-pretreated adolescent rats. Morphine pretreatment induces an opioid-sensitive current that shifts the reversal potential of the ME-induced conductance to more hyperpolarized potentials in both adolescent and adult rats $(* 0<0.05)$. (d) Bar graph showing the amplitude of ME-induced currents at $-40 \mathrm{mV}$. The opioid-sensitive cation current induced with morphine pretreatment is minimal at $-40 \mathrm{mV}$. There were no significant differences in amplitude of ME-induced GIRK currents at this potential in any group.

Hot plate latencies for each morphine-pretreated rat were compared to the mean for the morphine-pretreated rats and were split into two groups; rats with latencies that were faster than the mean (more tolerant) and rats with latencies slower than the mean (less tolerant). The amplitudes of the GIRK currents were larger in the recordings taken from the more tolerant group $(52.6 \pm 6.3 \%$ increase over control; $n=9$ ) than in recordings from the less tolerant group $(31.2 \pm 6.1 \% ; n=6 ; t(13)=2.333, p<0.05)$. This effect is not due to a higher sensitivity to morphine in the more tolerant group because there was no difference between hot plate latencies on Trial 1 in the more tolerant rats $(33.7 \pm 2.0 \mathrm{~s} ; n=9)$ compared to less tolerant rats $(35.7 \pm$ $3.0 \mathrm{~s} ; n=6$ ). There was also no significant difference in the reversal potentials in recordings from rats that were more or less tolerant $(-106.9 \pm 2.5 \mathrm{mV}$ and $-106.5 \pm 2.3 \mathrm{mV}$, respectively).

\section{DISCUSSION}

Adolescence in humans is associated with significant cognitive and psychological changes (Arnett, 1992) that result in a lack of impulse control and increased vulnerability to drug addiction (Chambers et al, 2003). Opiate use by adolescents has more than doubled in the past 10 years (Marsch et al, 2005), increasing the urgency for understanding how adolescents respond to opiate drugs. Periadolescence in rats is defined as the 7-10 days preceding the onset of puberty (day 40) (Spear and Brake, 1983; Laviola et al, 1999). The results in this study show that adolescent rats become tolerant to the antinociceptive effects of repeated injections of morphine and that adolescent rats may have an enhanced susceptibility to developing tolerance to repeated intermittent injections of morphine compared to adult rats.

Several factors may underlie the different baseline latencies on the hot plate test in early and late adolescent rats, including differences in neural innervation, nociceptive processing, body weights and/or paw surface areas. Hot plate latencies are inversely proportional to weight of the animal and this effect is consistent whether the comparison is by age or sex (Stoffel et al, 2003). Differences in baseline latencies disappeared by Trial 5 probably because early adolescent rats responded with faster latencies with repeated testing (Gamble and Milne, 1989) compared to late adolescent rats. We also minimized the effects of potentially different sensitivities of the groups to either the thermal stimulus or morphine-induced antinociception by only comparing shifts in $\mathrm{ED}_{50}$ after morphine pretreatment, not absolute $\mathrm{ED}_{50}$ values. This analysis shows that the development and extent of tolerance on the hot plate test was not significantly different for early and late adolescent rats. However, morphine-pretreated adult rats did not have as robust a shift in $\mathrm{ED}_{50}$ from saline-pretreated adult rats as was observed in the groups of adolescent rats (see Table 1).

The twofold shift in morphine $\mathrm{ED}_{50}$ in morphinepretreated rats is comparable to studies using repeated injections of morphine to induce tolerance in neonatal ( $\mathrm{Zhu}$ and Barr, 2003) and adult rats (Fernandes et al, 1977), although larger shifts can be induced with continuous administration of morphine (Thornton et al, 1997). There are reported differences in the earliest age that rats will display tolerance to morphine with some studies observing tolerance by postnatal day 7 (Barr and Wang, 1992) and other studies finding that tolerance could not be induced 
until postnatal day 15 (Fanselow and Cramer, 1988; Windh et al, 1995). It is likely that these differences are partly due to the different paradigms used for inducing tolerance and partly to developmental changes in cellular mechanisms of tolerance. $N$-methyl-d-aspartate (NMDA) receptor inhibitors, for example, block tolerance in rats that are approximately 2 weeks old, but have no effect on the expression of opioid tolerance in neonatal rats (Zhu and Barr, 2003). The advantage of this study is the within subjects design looking at both behavioral and cellular changes associated with repeated intermittent injections of morphine. The results show evidence that early adolescent rats develop robust tolerance to the antinociceptive effects of morphine and a trend toward larger shifts in the doseresponse to morphine compared to adults.

Consistent with the behavioral data, cellular changes after morphine pretreatment were similar between early and late adolescent rats. The dense tissue slices in rats older than 50 days make whole-cell patch-clamp recordings significantly more difficult than those from younger brains, precluding reliable recordings and comparison of cellular changes in adults. Surprisingly, the ME-induced outward currents were also of similar magnitude in morphine compared to salinepretreated rats. These data were unexpected because GIRK channels become uncoupled from postsynaptic $\mu$-opioid receptors after continuous morphine administration (Christie et al, 1987; Chieng and Christie, 1996). Although there was no change in amplitude, the ME-mediated currents reversed at more hyperpolarized potentials in morphine compared to saline-pretreated rats. These more negative potentials are consistent with previous data showing that continuous morphine administration induces a cAMP and PKA-dependent cation current associated with the GABA transporter (GAT1) in PAG neurons (Bagley et al, 2005). Opioid agonists inhibit this conductance by blocking adenylyl cyclase activity. The presence of a second opioidsensitive conductance indicates that ME-induced currents are a composite of opioid activation of GIRK channels and opioid inhibition of a cation conductance. We tested the possibility that the presence of the GAT-mediated current obscured a decrease in coupling of $\mu$-opioid receptors to GIRK channels in tolerant rats. However, the amplitudes of our ME-induced GIRK currents at $-40 \mathrm{mV}$, a potential where the nonselective cation current is minimal (Bagley et al, 2005), were also not different between tolerant and control rats. One reason for this discrepancy in $\mu$-opioid receptor coupling to GIRK channels may be that studies where decreased $\mu$-opioid receptor coupling to GIRK channels are observed use slow release preparations that release morphine constantly over 3-5 days (Christie et al, 1987; Chieng and Christie, 1996; Chieng and Williams, 1998; Ingram et al, 1998; Hack et al, 2003; Bagley et al, 2005). This would lead to a different pattern of opioid exposure compared to our repeated intermittent injection procedure, and longer opioid exposure may result in additional cellular changes that promote opioid receptor desensitization. Another difference is that our recordings are done 1-3 days after the last morphine injection instead of during continuous administration. Although maintaining the tissue in morphine is justified as necessary to prevent spontaneous withdrawal, there is no indication of spontaneous or naloxone-precipitated withdrawal behaviors either immedi- ately following the last morphine injection (Trial 5) or $24 \mathrm{~h}$ later (Ingram et al, 2005). Therefore, our paradigm of repeated intermittent administration of morphine preferentially induces changes associated with tolerance that persist for at least 1 week (Morgan et al, 2005).

One advantage of this study is that behavioral and electrophysiological measures of tolerance to morphine were assessed in the same rats. Further analysis of the ME-induced GIRK currents from morphine-pretreated rats indicated that rats with faster latencies than the mean on Trial 5 (more tolerant) displayed larger ME-induced currents than rats with slower latencies than the mean on Trial 5 (less tolerant). There was no difference between the groups in initial sensitivity to morphine (Trial 1) suggesting that $\mu$-opioid receptors may be coupled more strongly to effectors after morphine pretreatment and the development of tolerance. Given that $\mu$-opioid coupling to GIRK channels is decreased after continuous morphine pretreatment, coupling to effectors appears to be differentially regulated and is possibly dependent on the morphine administration procedure.

In sum, the results of this study demonstrate that adolescent rats develop rapid tolerance to repeated intermittent injections of morphine and that there is a trend for greater tolerance in younger rats. The cellular changes associated with tolerance are similar in early and late adolescent rats and likely involve increased coupling of $\mu$-opioid receptors to effectors. Future experiments are planned to determine which effectors are involved in the development of tolerance.

\section{ACKNOWLEDGEMENTS}

The authors thank Brad Tierney for technical support and Dr Paul Meyer for discussions on the manuscript. This work is supported by a NIDA grant (DA015498) and a NARSAD Young Investigator Award (SLI).

\section{REFERENCES}

Adriani W, Laviola G (2004). Windows of vulnerability to psychopathology and therapeutic strategy in the adolescent rodent model. Behav Pharmacol 15: 341-352.

Arnett J (1992). Reckless Behavior in Adolescence-a Developmental Perspective. Developmental Review 12: 339-373.

Bagley EE, Gerke MB, Vaughan CW, Hack SP, Christie MJ (2005). GABA transporter currents activated by protein kinase A excite midbrain neurons during opioid withdrawal. Neuron 45: 433-445.

Barr GA, Wang S (1992). Tolerance and withdrawal to chronic morphine treatment in the week old rat pup. Eur J Pharm 215: 35-42.

Basbaum AI, Fields HL (1984). Endogenous pain control systems: brainstem spinal pathways and endorphin circuitry. Annu Rev Neurosci 7: 309-338.

Blednov YA, Stoffel M, Alva H, Harris RA (2003). A pervasive mechanism for analgesia: activation of GIRK2 channels. Proc Natl Acad Sci USA 100: 277-282.

Campbell JO, Wood RD, Spear LP (2000). Cocaine and morphineinduced place conditioning in adolescent and adult rats. Physiol Behav 68: 487-493.

Chambers RA, Taylor JR, Potenza MN (2003). Developmental neurocircuitry of motivation in adolescence: a critical period of addiction vulnerability. Am J Psychiatr 160: 1041-1052. 
Chieng B, Christie MD (1996). Local opioid withdrawal in rat single periaqueductal gray neurons in vitro. J Neurosci 16: 7128-7136.

Chieng B, Christie MJ (1994). Hyperpolarization by opioids acting on mu-receptors of a sub-population of rat periaqueductal gray neurones in vitro. Br J Pharmacol 113: 121-128.

Chieng B, Williams JT (1998). Increased opioid inhibition of GABA release in nucleus accumbens during morphine withdrawal. J Neurosci 18: 7033-7039.

Christie MJ, Williams JT, North RA (1987). Cellular mechanisms of opioid tolerance: Studies in single brain neurons. Mol Pharmacol 32: 633-638.

Fanselow MS, Cramer CP (1988). The ontogeny of opiate tolerance and withdrawal in infant rats. Pharmacol Biochem Behav 31: 431-438.

Fernandes M, Kluwe S, Coper H (1977). The development of tolerance to morphine in the rat. Psychopharmacology (Berlin) 54: 197-201.

Fields HL, Heinricher MM, Mason P (1991). Neurotransmitters in nociceptive modulatory circuits. Annu Rev Neurosci 14: 219-245.

Fields HL, Malick A, Burstein R (1995). Dorsal horn projection targets of ON and OFF cells in the rostral ventromedial medulla. J Neurophysiol 74: 1742-1759.

Gamble GD, Milne RJ (1989). Repeated exposure to sham testing procedures reduces reflex withdrawal and hot-plate latencies: attenuation of tonic descending inhibition? Neurosci Lett 96: 312-317.

Hack SP, Vaughan CW, Christie MJ (2003). Modulation of GABA release during morphine withdrawal in midbrain neurons in vitro. Neuropharmacology 45: 575-584.

Heinricher MM, McGaraughty S, Grandy DK (1997). Circuitry underlying antiopioid actions of orphanin FQ in the rostral ventromedial medulla. J Neurophysiol 78: 3351-3358.

Ikeda K, Kobayashi T, Kumanishi T, Yano R, Sora I, Niki H (2002). Molecular mechanisms of analgesia induced by opioids and ethanol: is the GIRK channel one of the keys? Neurosci Res 44: 121-131.

Ingram SL, Tierney B, Morgan MM (2005). Analysis of compensatory changes in nociception, thermoregulation and activity during the development of tolerance to intermittent morphine administration. Program No. 801.1. 2005 Abstract Viewer/Itinerary Planner. Society for Neuroscience: Washington, DC, 2005.

Ingram SL, Vaughan CW, Bagley EE, Connor $M$, Christie MJ (1998). Enhanced opioid efficacy in opioid dependence is caused by an altered signal transduction pathway. $J$ Neurosci 18: 10269-10276.

Jacquet YF, Lajtha A (1974). Paradoxical effects after microinjection of morphine in the periaqueductal gray matter in the rat. Science 185: 1055-1057.

Jensen TS, Yaksh TL (1986). I. Comparison of antinociceptive action of morphine in the periaqueductal gray, medial and paramedial medulla in rat. Brain Res 363: 99-113.

Lane DA, Patel PA, Morgan MM (2005). Evidence for an intrinsic mechanism of antinociceptive tolerance within the ventrolateral periaqueductal gray of rats. Neuroscience 135: 227-234.

Laviola G, Adriani W, Terranova ML, Gerra G (1999). Psychobiological risk factors for vulnerability to psychostimulants in human adolescents and animal models. Neurosci Biobehav Rev 23: 993-1010.

Marker CL, Lujan R, Loh HH, Wickman K (2005). Spinal Gprotein-gated potassium channels contribute in a dose-depen- dent manner to the analgesic effect of mu- and delta- but not kappa-opioids. J Neurosci 25: 3551-3559.

Marsch LA, Bickel WK, Badger GJ, Stothart ME, Quesnel KJ, Stanger C et al (2005). Comparison of pharmacological treatments for opioid-dependent adolescents: a randomized controlled trial. Arch Gen Psychiatr 62: 1157-1164.

Marsh DF, Hatch DJ, Fitzgerald M (1997). Opioid systems and the newborn. Br J Anaesth 79: 787-795.

McQuay H (1999). Opioids in pain management. Lancet 353: 2229-2232.

Mitrovic I, Margeta-Mitrovic M, Bader S, Stoffel M, Jan LY, Basbaum AI (2003). Contribution of GIRK2-mediated postsynaptic signaling to opiate and alpha 2-adrenergic analgesia and analgesic sex differences. Proc Natl Acad Sci USA 100: 271-276.

Morgan MM, Fossum EN, Stalding BM, King MM (2006). Morphine antinociceptive potency on chemical, mechanical and thermal nociceptive tests in the rat. J Pain 5: 358-366.

Morgan MM, Tierney BW, Ingram SL (2005). Intermittent dosing prolongs tolerance to the antinociceptive effect of morphine microinjection into the periaqueductal gray. Brain Res 1059: 173-178.

Morgan MM, Whitney PK, Gold MS (1998). Immobility and flight associated with antinociception produced by activation of the ventral and lateral/dorsal regions of the rat periaqueductal gray. Brain Res 804: 159-166.

Osborne PB, Vaughan CW, Wilson HI, Christie MJ (1996). Opioid inhibition of rat periaqueductal grey neurones with identified projections to rostral ventromedial medulla in vitro. J Perinatol 490.2: 383-389.

Proudfit HK (1980). Reversible inactivation of raphe magnus neurons: effects on nociceptive threshold and morphine-induced analgesia. Brain Res 201: 459-464.

Smith RF (2003). Animal models of periadolescent substance abuse. Neurotoxicol Teratol 25: 291-301.

Spear LP, Brake SC (1983). Periadolescence: age-dependent behavior and psychopharmacological responsivity in rats. Dev Psychobiol 16: 83-109.

Spear LP, Horowitz GP, Lipovsky J (1982). Altered behavioral responsivity to morphine during the periadolescent period in rats. Behav Brain Res 4: 279-288.

Stoffel EC, Ulibarri CM, Craft RM (2003). Gonadal steroid hormone modulation of nociception, morphine antinociception and reproductive indices in male and female rats. Pain 103: 285-302.

Thornton SR, Wang AF, Smith FL (1997). Characterization of neonatal rat morphine tolerance and dependence. Eur $J$ Pharmacol 340: 161-167.

Windh RT, Little PJ, Kuhn CM (1995). The ontogeny of mu opiate tolerance and dependence in the rat: antinociceptive and biochemical studies. J Pharmacol Exp Ther 273: 1361-1374.

Yaksh TL, Yeung JC, Rudy TA (1976). Systematic examination in the rat of brain sites sensitive to the direct application of morphine: Observation of differential effects within the periaqueductal gray. Brain Res 114: 83-103.

Young EG, Watkins LR, Mayer DJ (1984). Comparison of the effects of ventral medullary lesions on systemic and microinjection morphine analgesia. Brain Res 290: 119-129.

Zhu H, Barr GA (2003). Ontogeny of NMDA receptor-mediated morphine tolerance in the postnatal rat. Pain 104: 437-447. 